\title{
Comportamento alimentar no campo da Alimentação e Nutrição: do que estamos falando?
}

| ${ }^{1}$ Juliana Klotz-Silva, ${ }^{2}$ Shirley Donizete Prado, ${ }^{3}$ Cristiane Marques Seixas |

Resumo: Comportamentos e hábitos alimentares são termos utilizados no campo da Alimentação e Nutrição, onde se destaca a ideia de autores que percebem os comportamentos como eventos controláveis e cuja repetição altera o hábito. Objetivase, neste ensaio, entender a influência dessa visão reducionista, destacando algumas discussōes sobre os comportamentos alimentares à luz das Ciências Humanas, em particular, da Psicologia e da Filosofia, para estabelecer uma diferenciação em relação aos hábitos alimentares. Ao problematizar o modo simplificado como essa questão é abordada, busca-se no paradigma da complexidade de Morin elementos para entender a relação entre comportamentos e hábitos alimentares, considerando formas de entendimento oriundas de outros campos de saber que não se reduzem à lógica simplificadora da ciência positivista tradicional. Na perspectiva do pensamento complexo, o comportamento se desloca de ação condicionada para uma extensão que comporta as dimensões sociocultural, subjetiva e individual, consciente e inconsciente, enquanto o hábito se afirma como aquilo que na repetição faz sentido para o indivíduo, permitindo que este possa apropriarse de forma singular das informações e orientações provenientes da ciência e sustentar suas mudanças.

> Palavras-chave: comportamento alimentar; hábito alimentar; diferença; repetição; Psicologia; Filosofia.

\author{
1 Instituto de Nutrição, \\ Universidade do Estado do Rio \\ de Janeiro. Rio de Janeiro-RJ, \\ Brasil (juju_klotz@yahoo. \\ com.br). \\ ${ }^{2}$ Instituto de Nutrição, \\ Universidade do Estado do Rio \\ de Janeiro. Rio de Janeiro-RJ, \\ Brasil (shirley.donizete.prado@ \\ gmail.com). \\ ${ }^{3}$ Universidade do Estado do Rio \\ de Janeiro. Rio de Janeiro-RJ, \\ Brasil (levemente@uol.com.br).
}

Recebido em: 18/12/2015 Aprovado em: 14/07/2016 
Os comportamentos alimentares estão na moda. Para entendê-los, tende-se a buscar referências no campo das Ciências Humanas e Sociais, numa tentativa de encontrar um caminho para o controle dos desejos e impulsos. No início do século XX, Watson (2008) propôs a ideia de que o objetivo principal da Psicologia seria o comportamento, sua previsão e controle. Essa ideia ainda se verifica, por exemplo, em estudos que buscam a solução para problemas relacionados à alimentação e valorizam o controle dos comportamentos, como se estivesse aí a garantia para o funcionamento adequado dos indivíduos. Neste texto, ${ }^{1}$ busca-se compreender a influência dessa visão reducionista no campo da Alimentação e Nutrição, destacando algumas discussões sobre os comportamentos alimentares à luz das Ciências Humanas, para estabelecer uma diferenciação em relação aos hábitos alimentares.

$\mathrm{Na}$ literatura do campo da Alimentação e Nutrição, encontram-se trabalhos que incluem tanto hábitos quanto comportamentos alimentares em suas explicações e conexões, de formas diversificadas (PACHECO, 2008; FREITAS et al., 2012; CARVALHO, 2012; KAMIL, 2013). Da mesma maneira, no campo das Ciências Humanas, as formas de entender esses dois termos também não são unívocas. Comportamento e hábito confundem-se em suas utilizações, quiçá em suas definições. De modo geral, o termo comportamento se tornou na atualidade quase domínio das teorias comportamentais, funcionando como sinônimo de ação. No campo das Ciências Sociais, vários estudos de cunho antropológico e sociológico dedicam-se a entender a relação dos hábitos alimentares com a cultura e a tradição em determinados grupos sociais, constituindo um importante campo de pesquisa (CANESQUI, 2005; CANESQUI; DIEZ-GARCIA, 2005; CARVALHO, 2012; DIEZ-GARCIA, 2005; FREITAS et al., 2012; PACHECO, 2008).

Segundo Bock, Furtado e Teixeira (2001), uma das dimensões da vida é o cotidiano, incorporada como um conhecimento: o senso comum. Como modos de produção de conhecimento, o senso comum e a ciência não são categorias absolutas, mas guardam estreita relação entre si. No dia a dia, o senso comum se apropria de diversas teorias, dentre elas as teorias científicas, ressignificadas livremente. Da mesma maneira, as teorias científicas originam-se de fatos da vida cotidiana, que passam a ser problematizados a partir dos modelos de conhecimento científico (BOCK; FURTADO; TEIXEIRA, 2001). 
Nesse sentido, pode-se considerar que, nos estudos relacionados ao campo da Alimentação e Nutrição, os termos "comportamentos alimentares" e "hábitos alimentares" são extraídos de seu uso no senso comum. São, portanto, categorias empíricas que expressam uma realidade, diferentemente das categorias analíticas, que se relacionam com conceitos e teorias estabelecidas (MINAYO, 2010). Para empreender os objetivos deste ensaio, buscaram-se referências teóricas para auxiliar na diferenciação desses dois termos, possibilitando utilizá-los como categorias de análise (CARVALHO, 2012). Ou seja, trata-se de destacar esses termos do uso coloquial, onde não há distinção entre um e outro, para constituir instrumentos com a sensibilidade que se faz necessária para analisar a polifonia desses termos no campo da Alimentação e Nutrição, "através de uma estratégia metodológica de conceituação" (CARVALHO; LUZ; PRADO, 2011, p. 156).

É seguindo essa proposta de conceituação que Klotz-Silva (2015) aborda a questão do hábito/costume e hábito/disposição, discutindo o conceito bourdieusiano de habitus e a presença de objetividade/subjetividade, permanência/ mudança e indivíduo/coletividade como elementos que podem trazer importantes contribuições para a compreensão dos hábitos alimentares, para além de visões simplificadoras que tendem a manter separações estanques entre o que é material e o que é dos afetos e valores. Para a autora, a ideia do hábito alimentar não pode ser restrita ao domínio individual, pois, uma vez inserido na cultura, o indivíduo é atravessado por disposições que o ultrapassam e o marcam de modo indelével.

Segundo Viana (2002), na interseção entre os campos da Psicologia e da Alimentação e Nutrição, um dos interesses que se destaca é relacionado aos transtornos alimentares e à obesidade, prevalecendo a ideia de que o comportamento alimentar dos indivíduos deve ser observado para a prevenção de doenças, uma vez que é repetidamente associado aos fatores de risco à saúde. O domínio dessa perspectiva da prevenção de comportamentos e hábitos patológicos no campo da Alimentação e Nutrição o torna terreno fértil para a adesão aos discursos biomédicos, tanto no que diz respeito à prática profissional, quanto no que tange à construção de explicações teóricas para fenômenos que não se reduzem à lógica simplificada de causa e efeito. $\mathrm{O}$ modelo científico positivista que domina o modo de fazer ciência em diversos campos e influencia sobremaneira o senso comum mostra-se incapaz de explicar de modo suficiente os hábitos e comportamentos patológicos. 
$\mathrm{Na}$ vastidão de formas de abordar as distorções do modelo científico positivista de explicação dos fenômenos humanos, Michael Gard e Jan Wright (2005) destacam, por exemplo, que o modelo explicativo para o fenômeno da atual "epidemia da obesidade" apresenta uma série de inconsistências e falhas. Os dados quantitativos das pesquisas não conseguem explicar a incoerência entre o substancial investimento em pesquisas sobre a obesidade e seu aumento estatístico significativo, o que coloca dificuldades em identificar os avanços científicos e sua eficácia. Para Seixas e Birman (2012), Gard e Wright enfatizam as contradições do discurso científico e explicam que as certezas e generalizaçôes científicas contribuem para a construção da "epidemia da obesidade". Uma dessas certezas é de que a obesidade é uma doença ocasionada por fraquezas individuais, ideia que é reforçada e disseminada pelo senso comum, dificultando ainda mais os tratamentos.

$\mathrm{Na}$ esteira dessas consideraçôes, pode-se identificar uma tendência à responsabilização dos indivíduos pelas mudanças nos hábitos e comportamentos alimentares (DIEZ-GARCIA, 2012; FRANCISCO; DIEZ-GARCIA, 2015) levando a um aumento no interesse por estudos no campo da Psicologia. Assim, modelos tradicionais da Psicologia - como, por exemplo, a Psicanálise e a Gestalt - que teriam como foco os processos internos e subjetivos do ser humano perdem espaço para abordagens mais afeitas ao modelo biomédico de explicação causal. Aqui, pode-se citar a Análise do Comportamento, a Terapia CognitivoComportamental e o Modelo Transteórico, nos quais a diferenciação entre comportamento e hábito alimentar se dá de forma naturalizada, numa prática discursiva do senso comum, visando somente à mudança de hábitos por meio da adequação do comportamento alimentar.

Dependendo de cada abordagem, hábitos e comportamentos alimentares podem ser analisados de formas iguais ou diferentes, com intenções e propósitos diversos, gerando uma indiferenciação que reduz o indivíduo a seu comportamento e estereotipa essas duas categorias de análise. É com esse incômodo que se realizou a leitura de trabalhos do campo da Alimentação e Nutrição, assim como da Psicologia e da Filosofia, para delimitar a relação entre o comportamento e o hábito alimentar, a fim de apreender seus modos de conceituação e seu uso no campo científico. 


\section{Comportamento alimentar no campo}

\section{Alimentação e Nutrição}

No campo da Alimentação e Nutrição, hábitos alimentares são relacionados à ideia de consumo alimentar ou, ainda, ingestão alimentar (ingestão energética e de nutrientes), enquanto o comportamento alimentar aparece, na maioria das vezes, relacionado aos aspectos psicológicos da ingestão de comida. A insuficiência de referências que busquem delimitar ou conceituar os termos aqui tratados aponta a necessidade de ampliar as discussōes sobre a interface entre os campos da Alimentação e Nutrição e das Ciências Humanas e Sociais, o que começa a ser realizado no interior de alguns grupos de pesquisa e também por pesquisadores isoladamente.

Partindo de uma breve revisão bibliográfica, identificaram-se pelo menos três chaves de leitura, que permitiram organizar os modos de utilização dos termos "comportamentos" e "hábitos alimentares" no campo da Alimentação e Nutrição, a fim de auxiliar o entendimento dos sentidos que estão aí dispersos.

\section{Repetição do comer}

Reconhecendo a indiferenciação dos termos supracitados no discurso cotidiano, Carvalho (2012), ao buscar estabelecer o uso do termo "hábito" no que concerne à alimentação, enxerga nítidas diferenças entre hábito e comportamento. Para a autora, os termos adquirem sentido dentro de um determinado contexto e são envolvidos por uma série de aspectos. Um deles é, sem dúvida, sua repetição no tempo e a possibilidade de um comportamento alimentar provisório ou ocasional se transformar em um hábito:

O comportamento alimentar implica uma ideia que pode ser profundamente específica de um modo de se alimentar, mas não tem uma preocupação com a duração da ação como a de hábito. Traduz uma prática sem a pretensão de situá-la no tempo, e dessa forma não expressa um processo contínuo, porque não tem a obrigação de relacionar um momento a outro - que se segue, o que não ocorre com a ideia de hábito alimentar (CARVALHO, 2012, p. 431 e 432).

A autora descreve que o comportamento pode ou não ser sucessivo. Já a noção de hábito tem a necessidade de repetição e uma ligação com o tempo. Os pontos levantados denunciam uma das influências da visão comportamentalista na Nutrição, que se expressa muitas vezes na ideia de que um nutricionista, ao propor "um tipo de alimentação [...] espera que o outro desenvolva um 
comportamento equivalente, e que em seguida este se torne um hábito alimentar" (CARVALHO, 2012, p. 431).

Nessa mesma linha, foram situados trabalhos que relacionam os hábitos ao cotidiano social e à cultura. Para Freitas et al. (2012), o hábito alimentar relaciona-se com a percepção sobre a comida em determinado contexto social, sendo adquirido pela repetição na experiência que cada indivíduo tem ao longo de sua vida. Vale destacar que os autores afirmam que o hábito alimentar traz uma intersubjetividade que se dá num nível pré-reflexivo, ou seja, não se limita à percepção racional ou a uma escolha intencional, mas é uma qualidade "onde o indivíduo tece uma infinita rede de símbolos que reflete sua realidade, o cotidiano de seu corpo, sua comida” (FREITAS et al., 2012, p. 35). Os autores entendem, assim, que hábitos e comportamentos podem ser parecidos e ter, ao mesmo tempo, diferenças de sentido.

Freitas et al. (2012) entendem que comportamentos e hábitos estão intimamente relacionados no que diz respeito à etiologia das doenças. Enquanto o primeiro situa-se na esfera da ação individual, inevitavelmente condicionada pela estrutura social e dela condicionante, o segundo relaciona-se com a experiência que se repete cotidianamente do indivíduo no social, um ato polissêmico que "faz parte de uma trama de significados do cotidiano em que o ser humano vive e no qual se encontra quase sempre cativo" (FREITAS et al., 2012, p. 36).

Diferentemente dos autores que buscam diferenciar hábito e comportamento, Pacheco (2008) analisa também os hábitos alimentares à luz da teoria de Bourdieu, indicando, contudo, uma estreita relação com o comportamento. Para a autora, o hábito é um comportamento, e este deriva de disposições incorporadas em nível pré-reflexivo e atua em escolhas que não são mecanizadas ou automatizadas, mas que são contextualizadas e se repetem no tempo. A autora indica que na Nutrição se entende que os hábitos são formados desde a infância e vão se modificando de acordo com o processo de socialização. Posteriormente, na adolescência, os hábitos alimentares se modificam na busca da identidade grupal e ao longo da vida sofrerão outras influências, mudanças e alteraçôes (PACHECO, 2008).

A criança cresce em um ambiente familiar que tem um comportamento alimentar definido, que se repete dia após dia e ao qual ela se adapta. [...] Ao sair do convívio basicamente familiar e penetrar no contexto escolar, o indivíduo experimentará outros alimentos e preparaçōes e terá oportunidade de promover alteraçōes nos seus hábitos alimentares... (PACHECO, 2008, p. 221). 
Observa-se, assim, a tentativa de delimitar diferenças e semelhanças, continuidades e descontinuidades entre comportamentos e hábitos alimentares sob a ótica de sua repetição no tempo e no contexto sociocultural. Ainda que não haja consenso, identificam-se tentativas de aprofundamento dessa discussão, agregando elementos das teorias sociais. Tal aspecto não fica evidente nos textos que tratam os hábitos e comportamentos alimentares numa perspectiva biomédica, como se discute a seguir.

\section{Ingestão de nutrientes}

Sob a influência da tradição biomédica no campo da Alimentação e Nutrição, aponta-se outra perspectiva, apresentada por alguns autores que associam as ideias de hábito e comportamento alimentar ao tipo de ingestão alimentar (RIBEIRO et al., 2011; PANZA et al., 2007; TORAL et al., 2006; KANNO et al., 2008; KAMIL, 2013). São trabalhos que se interessam por examinar que tipo de alimento determinado grupo ingere, a frequência e o modo, nomeando essa ingestão como hábito ou comportamento alimentar, indistintamente. Seu interesse expressa uma visão mais tradicional no campo da Nutrição, que entende o alimento como carreador de nutrientes e a análise apurada do hábito/ comportamento alimentar como aquilo que permite diagnosticar e tratar os problemas alimentares adequando a alimentação a uma norma cientificamente determinada de ingestão de alimentos. Aqui, não se observa uma preocupação em diferenciar hábito e comportamento, pois são tomados como se fossem sinônimos e como se seus sentidos fossem claros e autoevidentes.

Dentro dessa perspectiva da ingestão alimentar, é possível, porém, encontrar também uma problematização dessa forma mais estrita de entender o comer indicando a necessidade de ir além da ideia de ingestão de nutrientes e avançar nas discussões sobre as semelhanças e diferenças entre hábitos, práticas e comportamentos. Fischler (1995 apud POULAIN; PROENÇA; DIEZGARCIA, 2012), por exemplo, considera que o termo "hábitos alimentares" implica comportamentos mecânicos e "comportamento alimentar" costuma encarar questôes culturais por meio de aspectos deterministas. Assim, prefere o termo "práticas alimentares", em vez de comportamentos ou hábitos alimentares. Os autores criticam a visão de Fischler (1995), citado por eles, de evitar certas palavras devido ao uso que outros pesquisadores fazem delas. Para eles, por mais 
que algumas expressões sejam descritas simplificadamente, isso não é razão para não utilizá-las. Seria preciso, portanto, diferenciá-las melhor.

A fim de ampliar a visão sobre esses termos, Poulain, Proença e DiezGarcia (2012) agregam a caracterização do consumo alimentar nas práticas e comportamentos à sua conceituação. Ao incluir aspectos culturais e subjetivos do consumo nos comportamentos alimentares os autores extrapolam a visão mais tradicional do campo da nutrição, sem, contudo, diferenciá-los das práticas e dos hábitos alimentares.

\section{Psicologia dos transtornos}

Uma terceira chave de leitura proposta busca compreender a diferenciação entre comportamento e hábito alimentar a partir dos conceitos advindos da Psicologia. $\mathrm{Na}$ presente pesquisa, foram encontrados textos que relacionam o campo da Psicologia com a Nutrição para demonstrar as contribuições que uma área traz à outra no estudo dos comportamentos alimentares (VIANA, 2002; MOTTA; MOTTA; CAMPOS, 2012), sobretudo no manejo dos comportamentos patológicos e na promoção de hábitos alimentares saudáveis (TORAL; SLATER, 2007; FRANÇA et al., 2012; CAVALCANTI; DIAS; COSTA, 2005).

Nesses textos que fazem a interface com a Psicologia, a ideia de hábito é pouco problematizada e é utilizada como a mera repetição de um comportamento aprendido. $\mathrm{O}$ interesse volta-se prioritariamente para o comportamento alimentar em sua forma mais ampla, mas, na maioria das vezes, o comportamento é pensado a partir de seus aspectos patológicos, como aqueles que são observados nos transtornos alimentares (ALVARENGA; LARINO, 2002; GONÇALVES et al., 2013; LATTERZA et al., 2004; MARTINS et al., 2011; SILVA; PAPELBAUM, 2009; VILELA et al., 2004) e na obesidade (ADES; KERBAUY, 2002).

Como consequência da hegemonia de um modelo científico positivista, observou-se uma forte tendência a empreender uma leitura da realidade em que os conhecimentos são compartimentados em disciplinas, tornando-se ininteligíveis inclusive para especialistas de disciplinas próximas (MORIN, 2010; 2011). Ainda que nesses textos que se dedicam a entender os comportamentos patológicos se busque a interação entre os diversos saberes que tocam a questão da alimentação, fica evidente sua compartimentalização.

De modo geral, entende-se que a tentativa de relacionar esses dois campos é ainda incipiente, prevalecendo a lógica da fragmentação por especialidades. 
Ou seja, se um fenômeno não pode ser entendido pelo modelo biomédico que prevalece no campo da Nutrição, uma parte dele deve ser explicada pelas teorias socioantropológicas e outra parte pelas teorias psicológicas, separando a complexidade característica da alimentação em pequenas ilhas de conhecimento. $\mathrm{O}$ indivíduo, a partir desse ponto de vista, é tomado como um conjunto de partes que poderiam ser estudadas separadamente, e o conhecimento assim produzido poderia ser reunido a posteriori para integrar um todo inteligível.

\section{A complexidade da alimentação}

A alimentação mostra-se um fenômeno de difícil abordagem, que não se presta a generalizações ou explicações simplificadoras. $\mathrm{Na}$ tentativa de responder à incapacidade de abordar alguns problemas de modo simples, Edgar Morin (2010; 2011) constrói ao longo de sua trajetória intelectual o pensamento complexo. Rompendo com o paradigma da simplificação, que caracteriza o modo de produzir conhecimento de acordo com princípios científicos clássicos, como a ordem, a disjunção, a redução e a razão/lógica, Morin (2010) entende que a complexidade emerge justamente das fissuras do pensamento simplificador dominante, cujos paradoxos e contradições foram o estopim para a reconsideração de princípios científicos clássicos.

Segundo o autor, a solução de problemas complexos não reside em sua simplificação ou na descoberta de uma verdade última em um único campo de saber, mas na potencialização das contradições que lhe concernem. Para pensar o imprevisível e o incalculável, Morin propõe a quebra das barreiras disciplinares que estruturam o pensamento e o mutilam, reconhecendo o que liga e religa o objeto ao seu contexto, as partes ao todo e o todo às partes, rompendo com a tradição cartesiana que acaba reduzindo o complexo ao simples (MORIN, 2010; 2011).

Alheios ao paradigma da complexidade (que vem ganhando adeptos em vários campos de conhecimento) observou-se que tanto textos científicos quanto ações e políticas do campo da Alimentação e Nutrição permanecem regidos pela lógica da simplificação. Tratadas de modo simplificador e naturalizado, as questões concernentes à subjetividade, comportamentos e hábitos aparecem obrigatoriamente nos textos científicos e nas políticas públicas oficiais sem fundamento teórico, gerando uma proliferação de verdades que se generalizam tanto na ciência quanto no senso comum (KLOTZ-SILVA, 2015). 
Estudos como de Vaz e Bennemann (2014) ilustram tal condição do campo científico uma vez que partem de dados estatísticos relativos ao aumento do sobrepeso e da obesidade na população brasileira para fundamentar a necessidade de identificar significados e diferenças entre hábitos e comportamentos alimentares. A tarefa de "abordar esses conceitos de forma didática" (VAZ; BENNEMANN, 2014, p. 108), considerada pelos autores como objetivo do artigo e como essencial para prevenir, intervir e tratar os indivíduos, se mostra, ao fim e ao cabo, como mais uma descrição quantitativa dos artigos que tocam na temática, encontrados numa revisão bibliográfica, sem que se chegue, no entanto, a problematizar o conceito em si, ou a explicitar as ligações entre eles.

Já na Política Nacional de Alimentação e Nutrição (2013), onde problemáticas como os transtornos alimentares e a obesidade estão ligados a alterações no comportamento alimentar, destaca-se que a alimentação e a nutrição devem ser encaradas como determinantes de saúde e precisam "levar em conta a subjetividade e complexidade do comportamento alimentar" (BRASIL, 2013, p. 28). Por outro lado, seja em propostas internacionais relativas à alimentação saudável, atividade física e saúde (WHO, 2004), seja no recém-lançado Guia alimentar para a população brasileira (BRASIL, 2014), que coloca em prática as políticas que norteiam as açôes no campo da Nutrição e constitui, segundo o próprio guia, um importante instrumento de educação alimentar e nutricional no Sistema Único de Saúde (SUS), não foram localizadas as palavras subjetividade nem comportamento, apesar de haver uma ênfase em prescrever formas corretas de ser, agir e se alimentar.

\section{O enigma do comportamento}

Num esforço de diferenciar e ao mesmo tempo religar esses saberes fundamentais para a ampliação e consolidação do campo da Alimentação e Nutrição como campo científico, foram identificados diversos estudos no campo da Psicologia que falam sobre métodos de intervenção utilizados para modificação do comportamento alimentar. Nota-se que o behaviorismo é a base filosófica de muitas das atuais intervenções realizadas por profissionais tanto do campo da Psicologia quanto da Nutrição, tais como, a Análise do Comportamento, a Terapia Cognitivo-Comportamental (TCC) e o Modelo Transteórico. 
Na busca por uma base científica para a Psicologia, a origem do Behaviorismo com o manifesto de Watson (2008) está relacionada a uma tentativa de contestar os métodos subjetivos da Psicologia, que, no século XIX, constituíam as principais ferramentas da pesquisa científica (BAUM, 2007). O behaviorismo metodológico de Watson configura uma filosofia que visa combater a introspecção como método da Psicologia e inaugura uma nova forma de entendimento, baseada nas leis do condicionamento clássico, ou seja, considerando que o organismo responde de modo reflexo aos estímulos do ambiente (BAUM, 2007). A operação Estímulo-Resposta, que ganhou ênfase no modelo proposto por Watson, é levada ao extremo no behaviorismo radical (ou Análise do Comportamento) de Skinner (1982), quando admite uma perspectiva pragmática do comportamento: o comportamento operante. Skinner (1982) considera que, no comportamento operante, o homem age sobre o ambiente e este retroage sobre ele. Além disso, para que um comportamento continue ou pare, há a necessidade de um determinado tipo de reforço, como diz o autor:

\footnotetext{
Quando um comportamento tem um tipo de consequência chamada reforço, há maior probabilidade dele ocorrer novamente. Um reforçador positivo fortalece qualquer comportamento que o produza: um copo d'água é positivamente reforçador quando temos sede e, se então enchemos e bebemos um copo d'água, é mais provável que voltemos a fazê-lo em ocasiões semelhantes. Um reforçador negativo revigora qualquer comportamento que o reduza ou o faça cessar: quando tiramos um sapato que está apertado a redução do aperto é negativamente reforçadora e aumenta a probabilidade de que ajamos assim quando um sapato estiver apertado (SKINNER, 1982, p. 43).
}

Essa concepção de comportamento evidencia seu aspecto reducionista e dessubjetivado, que exclui as dimensões psicossociais do fenômeno humano. Entretanto, na esteira das críticas sofridas por esses teóricos, pode-se observar um alargamento das concepções do behaviorismo radical de Skinner. Na contemporaneidade, muitas vozes falam em nome da Terapia Comportamental; contudo, para Franks (2002), atualmente ela reflete uma combinação de procedimentos e métodos multidimensionais em vez de abordagens únicas, além de uma disposição para ultrapassar os limites rígidos do condicionamento tradicional. Seu enfoque permanece sendo a resolução de problemas, desde que a miríade de atuações clínicas mantenha suas bases em dados e predições comprovadas e não em intuições e impressões clínicas (FRANKS, 2002).

É nesse panorama que emergem estudos relativos ao tratamento dos comportamentos patológicos no campo da Alimentação e Nutrição que conjugam 
técnicas comportamentais e elementos mentais. Trata-se de novas soluções para o velho e conhecido problema da subjetividade: se um modelo de previsão e controle do comportamento que exclui os elementos mentais não é suficiente para eliminar os comportamentos indesejáveis, é preciso retomar algumas premissas, no caso, trata-se de incluir a cognição como elemento pessoal interno previsível e monitorável. Nesse sentido, o autor admite que técnicas mais atuais, como a Terapia Cognitiva de Beck, caem na órbita da Terapia Comportamental, na medida em que seguem seus preceitos fundamentais (FRANKS, 2002).

Assis e Nahas (1999) apresentam o Modelo Transteórico e a TCC no intuito de trazer informações sobre motivação e adesão em intervenções alimentares e que podem ser tomadas aqui como exemplos dessa modulação que a Terapia Comportamental sofreu na contemporaneidade.

O Modelo Transteórico, de James Prochaska, Carlo DiClemente e Norcross (1992) tem sido considerado promissor na abordagem do comportamento relacionado à saúde. Ainda que tenha sido elaborado originalmente para pesquisas com tabagistas (TORAL; SLATER, 2007), pois admite que a mudança de comportamento é processual e compreende cinco estágios (pré-contemplação, contemplação, preparação, ação e manutenção), sua utilização no manejo dos transtornos alimentares vem se ampliando. Duchesne e Almeida (2002, p. 49) analisam como a TCC pode ser utilizada em casos de transtornos alimentares por ser "uma intervenção semiestruturada, objetiva e orientada para metas, que aborda fatores cognitivos, emocionais e comportamentais no tratamento (...)" desses transtornos.

Observa-se que, em sua definição, a TCC indica a necessidade de ampliação da noção de comportamento, incluindo aspectos internos mais variados do que o Modelo Transteórico. Mantém, entretanto, a concepção tradicional de que o comportamento pode ser condicionado pela mudança de crenças e tornar-se, por repetição, um hábito.

Como o foco na maioria dos estudos sobre essas técnicas está nos resultados apresentados durante o período de tempo da intervenção, vale considerar aqui que poucas investigações fazem um acompanhamento no longo prazo dos resultados obtidos com essas abordagens e indicam a necessidade de realizá-los (DUCHESNE et al., 2007; KNAPP et al., 2007; WRIGHT et al., 2010). Da mesma maneira, observa-se que, em alguns livros sobre as técnicas e formas de 
aplicar a TCC, pode-se encontrar a indicação de que "mesmo os terapeutas mais experientes encontram dificuldades em estabelecer uma aliança terapêutica, conceituar as dificuldades corretamente e trabalhar de forma coerente em direção aos objetivos" (SILVA, 2014, p. 168).

Toral e Slater (2007) apontam também limitações no uso do Modelo Transteórico em relação aos comportamentos alimentares. Uma delas aponta que, diferentemente da aplicação do modelo para outros comportamentos aditivos, como o tabagismo, a alimentação não pode ser excluída da vida do indivíduo, mas precisa ser manejada para que se limite a uma alimentação saudável e adequada. Outra limitação seria que a maioria dos estudos que utilizam o Modelo Transteórico no comportamento alimentar não inclui outras dimensôes do comportamento, "tais como os processos de mudança, o equilíbrio de decisões e a autoeficácia do indivíduo” (TORAL; SLATER, 2007, p. 1647).

Apesar das críticas relativas a essas técnicas, elas são consideradas modelos hegemônicos de intervenção de fácil aplicação na área da saúde. Os efeitos da banalização desses modelos no senso comum não são menos significativos e alimentam a culpabilização dos indivíduos pelos fracassos nas mudanças de hábitos, descontextualizando-os de uma dinâmica psíquica mais abrangente.

\section{Do hábito ao comportamento}

Tendo em vista que as teorias científicas têm sua origem na problematização da vida cotidiana a partir do modelo de conhecimento científico (BOCK; FURTADO; TEIXEIRA, 2001), no que concerne ao hábito, do ponto de vista da Psicologia, ele vem sendo relacionado à repetição de ações ou comportamentos realizados pelos indivíduos. Grosso modo, no domínio da Psicologia geral, entende-se que o ser realiza uma ação e, por repetição, constitui seus hábitos cotidianos, vinculando agir e hábito numa série observável (JUNIOR; MELO, 2006).

Na perspectiva da construção social dos hábitos, é a repetição de uma forma de prática eficiente que produz o hábito, pois, devido à sua efetividade, ele tende a se manter e reproduzir, perpetuando determinadas práticas em uma tradição que passa através de gerações. Essa transmissão da tradição e do hábito se faz presente nas famílias, na educação e nas instituições de modo geral e tem uma função de manutenção de ideias dominantes (BOCK; FURTADO; TEIXEIRA, 2001).

A revisão apresentada explicita a perspectiva simplificadora com que o hábito 
tem sido tratado. Entretanto, seria essa a única maneira de compreender o hábito em sua relação com o comportamento? Na tentativa de restituir a complexidade própria aos comportamentos e hábitos alimentares, pode-se seguir o caminho trilhado por Deleuze (2006), que considera fundamental se questionar quanto à relação existente entre a ação e o hábito. Para levantar um questionamento relativo à própria gênese do ser, Deleuze se interroga se é agindo que os hábitos são adquiridos ou se, ao contrário, são adquiridos por meio da contemplação. Essa pergunta fundamenta-se em sua concepção de tempo, segundo a qual há uma síntese passiva do tempo, onde a contemplação é privilegiada na constituição do ser, em detrimento da ação. A partir da célebre frase de Hume, "a repetição nada muda no objeto que se repete, mas muda alguma coisa no espírito que a contempla” (DELEUZE, 2006, p. 111), Deleuze deduz e enfatiza a emergência da diferença na repetição e não a semelhança entre aquilo que aparentemente se repete. Diferentemente de tudo que se escuta na ciência positivista, para ele, a diferença é extraída da repetição pelo hábito como algo de novo que separa o primeiro objeto daquele que se repete.

A concepção de tempo apresentada por Deleuze difere da temporalidade linear que se utiliza tradicionalmente para observar certos fenômenos, pois indica que há uma síntese passiva do tempo que se constitui em contraçôes que ficam retidas e emitem expectativas que se relacionam intimamente com o hábito. Ou seja, quando Deleuze afirma que uma sequência se constitui pela repetição de elementos que se contraem e emitem a expectativa do novo acontecimento, afirma, outrossim, que o advento do novo elemento na sequência é, em última análise, uma inferência daquele que contempla, pois os eventos que se repetem são independentes em si mesmos.

É assim a síntese passiva que constitui nosso hábito de viver, isto é, nossa expectativa de que 'isto' continue, que um dos dois elementos ocorra após o outro, assegurando a perpetuação do nosso caso. Quando dizemos que o hábito é contração, não falamos, pois, da ação instantânea que se compõe com outra para formar um elemento de repetição, mas da fusão dessa repetição no espírito que a contempla (DELEUZE, 2006, p. 116).

A ideia do autor mais importante a ser destacada aqui é de que não há uma repetição em si mesma: é o aparecimento de um novo elemento que afirma o desaparecimento do anterior aos olhos daquele que contempla. Ele aponta 
que, se não há contemplação, o aparecimento desses mesmos elementos seria independente, mas se há contemplação há a indagação sobre a natureza desse elemento novo que surge. Segundo Junior e Melo (2006, p. 71), é a partir da experiência que se pergunta “como seria possível ordenar 'o segundo', 'o terceiro' e 'é o mesmo', já que a repetição não tem em-si, que não existe a priori? Não existir a priori indica: não é possível antes de qualquer experiência”.

Dessa forma, para Deleuze, o hábito constitui o ser e inaugura sua ontologia que desvia a subjetividade do lugar comum e do determinismo que se costuma a considerar. Se na Psicologia reducionista, assim como no campo da Alimentação e Nutrição, a subjetividade é considerada como algo que não exige um questionamento quanto à sua origem e constituição - podendo até mesmo ser eliminada ou controlada -, na concepção deleuzeana, observa-se uma inflexão na conceituação da subjetividade diferente das concepções simplificadoras do ser.

$\mathrm{Na}$ base das proposições de Deleuze está a crítica de Hume à razão como algo inquestionável. Para Hume, é o hábito que permite a dedução de que a existência de um objeto está ligada a outro, ou seja, a aparição de um sucede à de outro. A novidade deleuzeana que o diferencia de Hume está no fato de atribuir à repetição a condição de emergência da subjetividade como diferença (EIRADO, 1998; JUNIOR; MELO, 2006) e não como repetição. O apagamento do sujeito da ação na concepção tradicional de hábito é tributária de um projeto de cientificização e racionalização do humano e tem como efeito o reforço da ideia de que a ação intencional modifica por si só o hábito e, consequentemente, o indivíduo. Nessa perspectiva, o hábito como condição de existência se distingue do comportamento, não podendo ser, assim, manipulado de modo intencional ou mesmo condicionado.

Para o campo da Alimentação e Nutrição, considerar o hábito como o que possibilita a emergência da subjetividade na repetição implica considerar aquilo que faz sentido para cada indivíduo, ou seja, para que seja possível pensar em mudança de hábitos alimentares é preciso que a diferença, a singularidade individual tenha lugar privilegiado, e não seu apagamento característico dos comportamentos condicionados. Se uma nova atitude tem ancoragem no contexto social, na história e na vida de um indivíduo, é mais provável que elas se mantenham, pois funcionam como uma acomodação às demandas que a vida coloca (DIEZ-GARCIA, 2012). 
E como todas as coisas são causadas e causadoras, ajudadas e ajudantes, mediatas e imediatas, e todas se mantêm por um laço natural e insensível que liga as mais afastadas e as mais diferentes, tenho como impossível conhecer as partes sem conhecer o todo, bem como conhecer o todo sem conhecer as partes (MORIN, 2010, p. 191).

Integrar a necessidade cartesiana de separar as coisas para entendê-las e o princípio de Pascal citado acima por Morin é o desafio para o pensamento complexo. Para o presente trabalho, esse desafio implica interrogar o campo da Alimentação e Nutrição em seus aspectos conceituais que ficam submersos nas práticas cotidianas e não se prestam ao enfrentamento de seus paradoxos e contradiçôes. Se comportamentos podem ser alterados e com isso repetidos até tornarem-se hábitos, mas se isso não se confirma no longo prazo, qual seria de fato a relação entre hábitos e comportamentos? Qual seria o equívoco que o modelo de ciência positivista impóe aos pesquisadores?

Neste ensaio, limitamo-nos a um delineamento inicial de um problema que temos por relevante: a frequente - e mesmo hegemônica - abordagem simplificadora de objetos complexos, como é o caso do comportamento alimentar. Sem dúvida, fica a necessidade do aprofundamento dessa discussão a demandar novos olhares e cotejamentos de perspectivas teóricas e metodológicas outras que, além do biológico e médico, da causa e efeito, venham a considerar o que é da subjetividade, da cultura, da sociedade, do contraditório, do paradoxal. Nesse sentido, cabe enfatizar a necessidade de estudos voltados ao aprofundamento de reflexões de caráter conceitual, seja problematizando categorias empíricas correntes no campo da Saúde, seja propondo categorias analíticas dentro do objetivo de compreender relações sociais mediadas pela comida, por exemplo.

No campo da Alimentação e Nutrição, trata-se, portanto, de abordar o comportamento em sua relação com o hábito, não de forma simplificadora, mas considerando a complexidade da vida e do ser humano. A obstinação pela prevenção e pela cura que se apoia no uso ingênuo desses termos expõe com seu fracasso que o comportamento não pode ser controlado, o ser humano e seus hábitos não podem ser condicionados. Em suma, como Morin confirma: a simplicidade das partes não explica a complexidade do todo. Trata-se, como diz Morin, de "alguma coisa mais" (2010, p. 193) que precisa ser construída, deslocando a ação condicionada para uma dimensão que comporta a emergência 
da singularidade dos aspectos subjetivos e individuais. Nessa perspectiva, o

hábito poderia afirmar-se como aquilo que faz sentido, permitindo que o sujeito possa apropriar-se de forma singular das informações e orientações provenientes da ciência e sustentar suas mudanças. ${ }^{2}$

\section{Referências}

ADES, L.; KERBAUY, R. R. Obesidade: realidades e indagaçōes. Revista de Psicologia USP. São Paulo, v. 13, n. 1, p. 197-216, 2002.

ALVARENGA, M.; LARINO, M. A. Terapia nutricional na anorexia e bulimia nervosas. Revista Brasileira de Psiquiatria, v. 24, supl. 3, p. 39-43, 2002.

ASSIS, M. A. A.; NAHAS, M. V. Aspectos motivacionais em programas de mudança de comportamento alimentar. Revista de Nutrição. Campinas, v. 12, n. 1, p. 33-41, 1999.

BAUM, W. M. Compreender o behaviorismo: comportamento, cultura e evolução. Trad. Maria Teresa Araujo Silva et al. 2. ed. Porto Alegre: Artmed, 2007.

BOCK, A. M. B.; FURTADO, O; TEIXEIRA, M. L. T. Psicologias: uma introdução ao estudo de psicologia. 13. ed. São Paulo: Saraiva, 2001.

BRASIL. Ministério da Saúde. Secretaria de Atenção à Saúde. Departamento de Atenção Básica. Guia alimentar para a população brasileira. 2. ed. Brasília: Ministério da Saúde, 2014. 156 p. Disponível em: <http://189.28.128.100/dab/ docs/portaldab/publicacoes/ guia_alimentar_populacao_brasileira.pdf $>$. Acesso em: 18 abr. 2015.

. Política Nacional de Alimentação e Nutrição. Brasília, DF, 2013. 84 p. (Série B.

Textos Básicos de Saúde). Disponível em: http://bvsms.saude.gov.br/bvs/ publicacoes/ politica_nacional_alimentacao_nutricao.pdf. Acesso em: 18 abr. 2015.

CANESQUI, A. M. Comentários sobre os estudos antropológicos da alimentação. In: CANESQUI, A. M.; DIEZ-GARCIA, R. W. Antropologia e nutrição: um diálogo possível. Rio de Janeiro: Fiocruz, 2005. p. 23-47.

CANESQUI, A. M.; DIEZ-GARCIA, R. W. Ciências Sociais e Humanas nos cursos de Nutrição. In: . Antropologia e nutrição: um diálogo possível. Rio de Janeiro: Fiocruz, 2005. p. 255-274.

CARVALHO, M. C. V. S. Práticas e saberes na alimentação: natural, racional ou social? In: LUZ, M. T.; BARROS, N. F. Racionalidades médicas e práticas integrativas em saúde, estudos teóricos e empiricos. Rio de Janeiro: Cepesc, 2012. p.425-442.

CARVALHO, M. C. V. S.; LUZ, M. T.; PRADO, S. D. Comer, alimentar e nutrir: categorias analíticas instrumentais no campo da pesquisa científica. Revista Ciência \& Saúde Coletiva, v. 16, n. 1, p. 155-163, 2011. 
CAVALCANTI, A. P. R.; DIAS, M. R.; COSTA, M. J. C. Psicologia e nutrição: predizendo a intenção comportamental de aderir a dietas de redução de peso entre obesos de baixa renda. Estudos de Psicologia. Natal, v. 10, n. 1, p. 121-129, 2005.

DELEUZE, G. Diferença e repetição. 2. ed. Rio de Janeiro: Graal, 2006.

DIEZ-GARCIA, R. W. A antropologia aplicada às diferentes áreas da nutrição. In: CANESQUI, A. M.; DIEZ-GARCIA, R. W. Antropologia e nutrição: um diálogo possível. Rio de Janeiro: Fiocruz, 2005. p. 275-286.

Mudanças alimentares: implicações práticas, teóricas e metodológicas. In: DIEZ-GARCIA, R. W.; CERVATO-MANCUSO, A. M. Mudanças alimentares e educação nutricional. Rio de Janeiro: Guanabara Koogan, 2012. p. 3-17.

DUCHESNE, M. et al. Evidências sobre a terapia cognitivo-comportamental no tratamento de obesos com transtorno da compulsão alimentar periódica. Revista de Psiquiatria do Rio Grande do Sul. Porto Alegre, v. 29, n. 1, p. 80-92, 2007.

DUCHESNE, M.; ALMEIDA, P. E. M. Terapia cognitivo-comportamental dos transtornos alimentares. Revista Brasileira de Psiquiatria, v. 24, supl. 3, p. 49-53, 2002.

EIRADO, A. O Hábito do ponto de vista ontológico e a produção de subjetividade. Revista do Departamento de Psicologia - UFF, v. 10, n. 1, p. 4-8, 1998.

FISCHLER, C. El (H)omnívoro. El gusto, la cocina y el cuerpo. Barcelona: Anagrama, 1995.

FRANÇA, C. L. et al. Contribuiçôes da psicologia e da nutrição para a mudança do comportamento alimentar. Estudos de psicologia. Natal, v.17, n.2, p. 337-345, 2012.

FRANCISCO, L. V.; DIEZ-GARCIA, R. W. Abordagem terapêutica da obesidade: entre conceitos e preconceitos. Demetra: Alimentação Nutrição e Saúde. Rio de Janeiro, v. 10, n. 3, 705-716, 2015.

FRANKS, C. M. Origens, história recente, questôes atuais e estados futuros da terapia comportamental: uma revisão conceitual. In: CABALLO, V. E. Manual de Técnicas de Terapia e Modificação do Comportamento. São Paulo: Livraria Santos Editora, 2002. p. 3-22. FREITAS, M. C. S. et al. Hábitos alimentares e os sentidos do comer. In: DIEZ-GARCIA, R. W.; CERVATO-MANCUSO, A. M. Mudanças alimentares e educação nutricional. Rio de Janeiro: Guanabara Koogan, 2012. p. 35-42.

GARD, M.; WRIGHT, J. The obesity epidemic: science, morality and ideology. London: Routledge, 2005.

GONÇALVES, J. A et al. Transtornos alimentares na infância e na adolescência. Revista paulista de pediatria, v. 31, n. 1, p. 96-103, 2013.

JUNIOR, A. M.; MELO, D. A. S. A fundação do subjetivo: o hábito para além da Psicologia. Revista do Departamento de Psicologia-UFF, v. 18, n. 2, p. 69-82, 2006. 
KAMIL, J. M. Hábito e comportamento alimentar de escolares do $5^{\circ}$ ano do ensino fundamental residentes em Juiz de Fora - MG. 2013. 95 f. Dissertação (Mestrado em Psicologia) - Instituto de Ciências Humanas, Universidade Federal de Juiz de Fora, Juiz de Fora, 2013.

KANNO, P. et al. Discrepâncias na imagem corporal e na dieta de obesos. Revista de Nutrição, Campinas, v. 21, n. 4, p. 423-430, 2008.

KLOTZ-SILVA, J. Hábitos alimentares e comportamento alimentar: do que estamos falando? 2015. 75 f. Tese (Doutorado em Alimentação, Nutrição e Saúde) - Instituto de Nutrição, Universidade do Estado do Rio de Janeiro, Rio de Janeiro.

KNAPP, P. et al. Terapia cognitivo-comportamental na prática psiquiátrica. Porto Alegre: Artmed, 2007.

LATTERZA, A. R et al. Tratamento nutricional dos transtornos alimentares. Revista de psiquiatria clinica, v.31, n.4, p. 173-176, 2004.

MARTINS, M. C. T. et al. Ortorexia nervosa: reflexões sobre um novo conceito. Revista de Nutrição, v. 24, n. 2, p. 345-357, 2011.

MINAYO, M. C. S. Conceitos para operacionalização da pesquisa. In: O desafio do conhecimento: pesquisa qualitativa em saúde. 12. ed. São Paulo: Hucitec, 2010. p. 175-181.

MORIN, E. Introdução ao pensamento complexo. 4. ed. Porto Alegre: Sulina, 2011. . Meu caminho: entrevistas com Djénane Kareh Tager. Rio de Janeiro: Bertrand Brasil, 2010.

MOTTA, D.; MOTTA, C.; CAMPOS, R. Teorias psicológicas da fundamentação do aconselhamento nutricional. In: DIEZ-GARCIA, R. W; CERVATO-MANCUSO, A. M. Mudanças alimentares e educação nutricional. Rio de Janeiro: Guanabara Koogan, 2012. p. 53-65.

PACHECO, S. S. M. O hábito alimentar enquanto um comportamento culturalmente produzido. In: FREITAS, M. C. S.; FONTES, G. A. V.; OLIVEIRA, N. (Org.). Escritas e Narrativas sobre Alimentação e Cultura. Salvador: EDUFBA, 2008. p. 217-238.

PANZA, V. P. et al. Consumo alimentar de atletas: reflexões sobre recomendações nutricionais, hábitos alimentares e métodos para avaliação do gasto e consumo energéticos. Revista de Nutrição, v. 20, n. 6, p. 681-692, 2007.

POUlAIN, J.-P.; PROENÇA, R. P. C; DIEZ-GARCIA, R. W. Diagnóstico das práticas e comportamento alimentares: aspectos metodológicos. In: DIEZ-GARCIA, R. W; CERVATO-MANCUSO, A. M. Mudanças alimentares e educação nutricional. Rio de Janeiro: Guanabara Koogan, 2012. p. 149-163.

PROCHASKA, J.O.; DICLEMENTE, C.C.; NORCROSS, J.C. In search of how people change - applications to addictive behaviors. Am Psychol, v. 47. n. 9, p. 1102-1114, 1992. 
RIBEIRO, M. M. C. et al. Impacto do hábito de jantar sobre o perfil dietético de pacientes em hemodiálise. Jornal Brasileiro de Nefrologia, v. 33, n. 1, p. 69-77, 2011.

SEIXAS, C. M.; BIRMAN, J. O peso do patológico: biopolítica e vida nua. História, Ciências, Saúde-Manguinhos, v. 19, n. 1, p. 13-26, 2012.

SILVA, M. A. Terapia Cognitiva-Comportamental: da teoria a prática. Psico-USF, Itatiba, v. 19, n. 1, p. 167-168, 2014.

SILVA, V. G; PAPELBAUM, M. Fobia alimentar associada a magreza: um diagnóstico diferencial com anorexia nervosa. Jornal brasileiro de Psiquiatria, v. 58, n. 3, p. 205-208, 2009. SKINNER, B. F. Sobre o Behaviorismo. São Paulo: Cultrix/EDUSP, 1982.

TORAL, N. et al. Comportamento alimentar de adolescentes em relação ao consumo de frutas e verduras. Revista de Nutrição, v. 19, n. 3, p. 331-340, 2006.

TORAL, N.; SLATER, B. Abordagem do modelo transteórico no comportamento alimentar. Ciência e Saúde Coletiva, v. 12, n. 6, p. 1641-1650, 2007.

VAZ, D. S. S.; BENNEMANN, R. S. Comportamento alimentar e hábito alimentar: uma revisão. Revista UNINGÁ Review, v. 20, n. 1, p. 108-112, 2014.

VIANA, V. Psicologia, saúde e nutrição: contributo para o estudo do comportamento alimentar. Análise Psicológica, v. 20, n. 4, p. 611-624, 2002.

VILELA, J. E. M. et al. Transtornos alimentares em escolares. Jornal de Pediatria, v. 80, n. 1, p. 49-54, 2004.

WATSON, J. B. Clássico traduzido: a psicologia como o behaviorista a vê. Temas em psicologia, Ribeirão Preto, v. 16, n. 2, p. 289-301, 2008.

WORLD HEALTH ORGANIZATION. Estratégia global em alimentação saudável, atividade física e saúde. 57ª Assembleia Mundial de Saúde, 25 mai 2004.

WRIGHT, J. et al. Terapia cognitivo-comportamental para doenças mentais graves. Porto Alegre: Artmed, 2010.

\section{Notas}

${ }^{1}$ Este texto deriva da tese de doutorado de Juliana Klotz-Silva, desenvolvida no Programa de PósGraduação em Alimentação, Nutrição e Saúde do Instituto de Nutrição, Universidade do Estado do Rio de Janeiro. Agradecemos o apoio financeiro da CAPES, através de bolsa de doutorado, do CNPq, da FAPERJ e do Programa PROCIÊNCIA-UERJ.

2 J. Klotz-Silva participou da concepção do estudo, realizou a pesquisa bibliográfica e a redação do artigo. S. D. Prado participou da concepção e orientação do estudo, contribuiu com a redação e aprovação final do manuscrito. C. M. Seixas participou da concepção e orientação do estudo, contribuiu com a discussão teórica e redação final do artigo. 


\section{Abstract}

Eating behavior in the field of Food and Nutrition: what are we talking about?

Behaviors and eating habits are terms used in the field of Food and Nutrition, where authors perceive behaviors as controllable events and that repetition changes habits. This essay aims to understand the influence of this reductionist approach, highlighting some discussions about eating behaviors in light of Humanities, in particular Psychology and Philosophy, in order to distinguish it from eating habits. To discuss the simplified way this issue is addressed, it was sought elements on the paradigm of the complexity of Morin to understand the relationship between eating behaviors and eating habits, taking into account other strands of understanding coming from other fields of knowledge that are not reduced to simplistic logic of the traditional positivist science. From the perspective of complex thought, behavior moves from conditional action to an extension that comprises socio-cultural, subjective and individual, either conscious or unconscious dimensions, while the habit is something that makes sense in repetition for the individual, appropriating information from science to support their changes.

Keywords: food behavior; eating habits; difference; repetition; Psychology; Philosophy. 